\title{
A REDE SOCIAL DE UM EMPREENDIMENTO SOCIAL COLETIVO
}

\section{ARTIGO ORIGINAL}

ALMEIDA, Vanessa Fernanda Rios De ${ }^{1}$

MEDRADO, Sara Dos Santos ${ }^{2}$

MATOS, Gleimiria Batista Da Costa ${ }^{3}$

ANZILIERO, Flávia Cristina Do Nascimento ${ }^{4}$

BOMBARDELLI, Joel ${ }^{5}$

BRAGA, lluska Lobo ${ }^{6}$

1 Mestra em Administração; Especialista em Gestão Financeira, Controladoria e Auditoria Fiscal e Contábil; Especialista em Planejamento Estratégico na Gestão Pública, Graduada em Ciências Contábeis.

${ }^{2}$ Mestra em Administração; Especialista em Docência no Ensino Superior; Graduada em Administração.

3 Doutora em Desenvolvimento Regional; Mestra em Desenvolvimento Regional e Meio Ambiente; Graduada em Ciências Contábeis.

4 Especialista em Planejamento Estratégico na Gestão Pública; Graduada em Secretariado.

${ }^{5}$ Doutor em Ciências da Linguagem; Mestre em Engenharia de Produção; Graduado em Ciências Contábeis.

6 Doutora em administração; Mestra em Administração; Graduada em Ciências Contábeis. 
ARENAS, Marlene Valério Dos Santos ${ }^{7}$

ALMEIDA, Vanessa Fernanda Rios De. Et al. A Rede Social de um empreendimento social coletivo. Revista Científica Multidisciplinar Núcleo do Conhecimento. Ano 05, Ed. 10, Vol. 13, pp. 175-191. Outubro de 2020. ISSN: 2448-0959, Link de acesso: https://www.nucleodoconhecimento.com.br/administracao/rede-social

\section{RESUMO}

As redes sociais são completas por tratar do conjunto de pessoas conectadas por relacionamentos sociais. Ainda não existe cultura nos estudos sobre os empreendimentos sociais coletivos, mas são esses um modelo de negócio que busca o bem-estar social e ambiental, beneficiando diretamente a parcela da população que faz parte do projeto e de forma indireta todos aqueles que passam a ter maior qualidade de vida através dos benefícios disponibilizados pelo empreendimento social. Nesse estudo o empreendimento investigado é uma associação denominada ASPROVEL, localizada no município de Porto Velho, estado de Rondônia; pioneira no Estado trabalhando com catadores. O objetivo da pesquisa é demonstrar a importância da rede social na trajetória de um empreendedorismo social coletivo. $\mathrm{O}$ arcabouço teórico buscou-se teoria referentes a empreendedorismo social, empreendedorismo social coletivo, redes sociais e formação e desenvolvimento de redes. A metodologia da pesquisa é de caráter exploratória, com abordagem qualitativa. Os resultados encontrados foram principalmente que a força da associação está na rede de apoio e na legitimação que possui diante a sociedade e não nos seus associados, vez que a cooperação e a intenção de estar junto para conseguir melhores posições no mercado ainda não é mais forte que o medo de estar junto e perder uma vez para ganhar muitas.

7 Doutora em administração; Mestra em Engenharia da Produção; especialista em Metodologia de Ensino Superior; Graduada em Ciências Contábeis, em Administração, em Esquema I-licenciatura de $1^{\circ}$ e $2^{\circ}$ graus. 
Palavras-chave: Rede, social, empreendimento, cooperativa.

\section{INTRODUÇÃO}

As redes sociais são habitualmente confundidas com mídias sociais, inclusive na academia, essa confusão acontece pela popularização e disseminação do termo redes sociais como sinônimo de mídias sociais. Portanto, nesse estudo redes sociais é utilizado no sentido de estrutura social integrada por pessoas e/ou organizações, conectadas por diversos tipos de relações.

Empreendimentos sociais coletivos diferente dos empreendimentos convencionais onde a principal estimulo é o lucro para os sócios e a geração de crescimento econômico mesmo que afetando negativamente outros setores fundamentais para a manutenção humana na terra, os empreendimento sociais coletivos tem seu principal incentivo pautado no bem-estar social, onde todos os envolvidos possam ser beneficiados por suas atividades, as atividades assim como nos empreendimentos convencionais podem ser inovadores ou não. Esse tipo de empreendimento causa impacto e mudanças para aqueles que são afetados diretamente e para aqueles que indiretamente está inserido no contexto onde é desenvolvido as atividades; os empreendimentos sociais coletivos tem o pensamento sistêmico para disseminação e compreensão dos seus princípios, o ganho para os beneficiários e comunidade é material e imaterial. Esse modelo de negócio é aliado à sustentabilidade ambiental e inserção social daqueles visto a margem da sociedade, visto que atual como uma ferramenta de mudança visto que atua nas atividades comerciais que integram objetivos sociais, econômicos, culturais, ambientais e políticos.

As redes sociais de uma empreendimento social coletivo, colabora na construção do empreendimento, gerando confiança, transparência e credibilidade diante das parcerias estratégicas que pode ter surgido no decorrer da construção e aprimoramento do empreendimento, a construção da rede acontece de maneira natural e intencional simultaneamente, o empreendedor social não percebe a como a rede está sendo construída no exato momento em que os eventos estão acontecendo. 
Assim como os empreendedores convencionais, os empreendedores sociais percebem uma necessidade de dada população e tende a buscar soluções para supera-las, no primeiro momento os empreendedores sociais fazem o estudo do problema e tendem a buscar soluções não convencionais, buscando que os benefícios sejam para todos os envolvidos, mesmo que de forma indireta. Estar em um empreendimento social coletivo faz com quem os membros tenham autonomia e ainda assim estejam recebendo ajuda mútua, aumentam o poder de barganha diante dos fornecedores e clientes finais e participam de convênios beneficiam todos os participantes do empreendimento social coletivo, diante do exposto e da necessidade de estudos que abordem a construção de empreendimentos sociais coletivos a presente pesquisa tem o objetivo de demonstrar a importância da rede social na trajetória de um empreendedorismo social coletivo.

\section{DESENVOLVIMENTO}

\subsection{EMPREENDEDORISMO SOCIAL COLETIVO}

Desempenhando papel relevante na economia, empreendedorismo é frequentemente definido como a busca oportunista de riqueza econômica através de iniciativas criativas do indivíduo operando em um ambiente incerto limitado por recursos tangíveis limitados, em que cria-se novas formas de atividades econômicas, muitas vezes por meio da criação de uma nova organização (MITCHELL et al., 2002; REYNOLDS, 2005; AUSTIN et al., 2006).

Peredo e McLean (2006), apontam para uma forma de criação de valor além da maximização dos lucros como é mensurado nos empreendimentos comerciais, este trata da criação de valor social, considerado como mecanismo importante para o desenvolvimento da sociedade, e que é proporcionado pelo empreendimento social. Com uma abrangência além do assistencialismo para os problemas sociais, o empreendedorismo social, para Bessant e Tidd (2009), promove mudanças sustentável com a formação de estruturas que oferecem modelos alternativos e viáveis. 
Empreendedorismo social pode ser entendido como um conjunto de atividades que proporciona valor social, mesclando abordagens empreendedoras e inovadoras (BROUARD e LARIVET, 2011). O contexto social é impactado pela ação do empreendedor, uma vez que "[...] o desempenho do empreendedor é influenciado ou condicionado pela natureza das suas redes de imersão social, [...] e por seus atributos pessoais" (CORREA e VALE, 2014, p. 78).

Novos modelos de negócios surgem frente a preocupação com a sustentabilidade ambiental e a inclusão social. O empreendedorismo social coletivo é tido como ferramenta de mudança sócio-político, que se refere a atividades comerciais que integram objetivos sociais, econômicos, culturais, ambientais e políticos (CONNELL, 1999; CHOUINARD e FORGUES, 2002).

O processo de empreendedorismo social coletivo envolve a visão, o engajamento e a divulgação dos objetivos para que se haja mudanças que promovem o desempenho sustentável, ou seja, desenvolvimento social, econômico e ambiental (THOMPSON, 2002). O empreendedor social está comprometido com sua visão social, e está sempre engajado na busca por soluções aos problemas sociais, mesmo enfrentando restrições ideológicas ou de recursos. O processo envolve demonstrar compromisso através de redes sociais para aproveitar a confiança, transparência e credibilidade. Parcerias estratégicas são cruciais para angariar apoio de base, participação e legitimação da missão social (GLIEDT e PARKER, 2007). As redes sociais também são um meio para recursos emocionais, financeiros e humanos. $O$ processo de capacitação inclui a aquisição de financiamento e treinamento de recursos humanos para sustentar a visão social.

As redes sociais formam um recurso inestimável para os empreendedores sociais coletivos para aconselhamento, recursos humanos, ideias, capacidades inovadoras, apoio financeiro e emocional (GREVE e SALAFF, 2003; NAHAPIET e GHOSHAL, 1998). Para Nahapiet e Ghoshal, 1998, esse capital social divide-se em três dimensões: a) estrutural, em que as redes sociais fornecem um sistema em que a missão do empreendedor é incorporada e disseminada. Os laços de rede permitem um rico compartilhamento de informações e conhecimento para criar soluções mais 
inovadoras e relevantes para atender os benefícios da comunidade em geral. b) relacional, onde a participação ativa nas redes induz a aprendizagem coletiva e promove uma melhor compreensão das normas da comunidade social; e c) cognitiva, que diz respeito à derivação de significados compartilhados em contextos particulares.

Visto como empreendedor cidadão pautado por uma consciência social, tem como objetivo obter êxito em seus projetos socialmente inovadores e economicamente sustentáveis, para propiciar melhoria de vida a pessoas marginalizadas, promovendo desenvolvimento social (OLIVEIRA, 2013). Para Bessant e Tidd (2009) os empreendedores sociais diferem-se dos tradicionais pois: (i) preocupam-se mais com os meios e os fins sociais do que apenas a obtenção de lucros; (ii) sabem que os resultados advêm a longo prazo e por isso buscam por resultados duradouros; e (iii) procuram parcerias para obter recursos que corroborem com a finalidade de desenvolvimento de mudanças.

Os empreendedores sociais enfrentam inúmeros limitações de recursos (materiais e não materiais), como também operam em contextos onde enfrentam barreiras culturais e vazios institucionais (MAIR e MARTI 2009). Se atuarem de forma isolada, negligenciarão o papel vital desempenhado por atores, redes, organizações e instituições externas na superação desses obstáculos (SPEAR 2006). Nessa perspectiva, grande parte do empreendedorismo social parece, de fato, ser colaborativo e coletivo, valendo-se de uma ampla gama de apoio, cooperação e alianças para construir consciência, ganhar recursos e, em última análise, fazer mudanças (SUD et al., 2009; VANSANDT et al., 2009). Assim, O empreendedorismo social coletivo serve para alavancar os recursos existentes, construir novos recursos e impactar o surgimento e a reformulação de arranjos institucionais para apoiar esforços redimensionáveis de mudança.

O papel dos empreendedores sociais coletivos na busca por mudanças sociais pode assumir muitas formas. Montgomery, Dacin e Dacin (2012) apontam três formas como sendo as principais para a ação coletiva conforme Quadro 1: 
Quadro 1: Formas de ações coletivas na busca por mudanças sociais

\begin{tabular}{|l|l|}
\hline MOVIMENTOS SOCIAIS & $\begin{array}{l}\text { As conexões e o apoio entre as organizações } \\
\text { fornecem canais para que ideias e práticas se } \\
\text { espalhem, obtenham apoio e legitimidade e, } \\
\text { finalmente, se tornem institucionalizadas e } \\
\text { efetuem mudanças. }\end{array}$ \\
\hline COOPERATIVAS & $\begin{array}{l}\text { Permite que grupos variados de consumidores, } \\
\text { COMUNITÁRIAS }\end{array}$ \\
organizações e movimentos colaborem para \\
melhorar o bem-estar social e econômico dos \\
cidadãos locais. \\
\hline INTEORGANIZACIONAL
\end{tabular}

Fonte: adaptado de Montgomery, Dacin e Dacin (2012).

Todas essas formas de ação coletiva destacam a importância de adquirir e implantar recursos de vários atores por meio de diversas atividades e estratégias para compartilhar ideias, mobilizar apoiadores, reunir diversos pontos de vista e colaborar para impulsionar a mudança. Os empreendimentos sociais coletivos bem-sucedidos muitas vezes alavancam simultaneamente muitas dessas formas existentes, incluindo o uso de modelos cooperativos, o desenvolvimento de colaborações entre setores e o aproveitamento dos movimentos sociais existentes (MONTGOMERY; DACIN e DACIN, 2012).

Quanto as cooperativas comunitárias, Pedrozo e Silva (1999) afirmam que, como estas trabalham com o princípio da cooperação, acabam tendo condições diferenciadas para trabalhar o princípio da sustentabilidade, pois soma habilidades e esforços, geração de renda, ajuda mútua na busca por qualidade de vida dos cooperados, bem como ganhos para a comunidade em que se insere. 
Contudo, ainda que considerando esses valores e princípios para a formulação e sucesso do empreendedorismo sócias coletivo, existem obstáculos que dificultam e enfraquecem esses modelos de negócios. Singer (2000) alerta que, na maioria das vezes os tipos de empreendimentos são constituídos por trabalhadores com baixa escolaridade, que possuem considerável experiência no processo produtivo, mas que não possuem conhecimentos em processos administrativos, mercado, gestão, tampouco na evolução tecnológico de produtos e processos. Como consequência, essas fraquezas podem reduzir o desempenho dos empreendimentos e sua capacidade de geração de excedentes que é o que proporciona autonomia econômica dos seus membros.

\subsection{REDES SOCIAIS}

O que concerne ao conceito de redes sociais, segundo Nohria (1992), vem sendo estudado sistematicamente desde a década de 1950 por vários campos de estudos, como por exemplo a psicologia, sociologia, antropologia e biologia molecular. Derivada do termo em latim retis, a palavra rede ganha múltiplos significados conforme cada autor, porem todos convergem para o mesmo entendimento, qual seja, o entrelaçamento de fios por um conjunto de nós interconectados com aberturas regulares que formam uma espécie de tecido (FERNADES, 2005; OLIVEIRA e CANDIDO 2006).

Emergente do resultado de uma estrutura composta das interações entre pessoas, grupo de pessoas e/ou organizações conectadas por algum tipo de relação no compartilhamento de objetivos e valores comuns (MARTELETO, 2001; JUNQUEIRA, 2000), as redes sociais visam "[...] responder às demandas e às necessidades da população de maneira integrada, respeitando o saber e a autonomia de cada membro" (JUNQUEIRA, 2000, p. 40).

Composta por agentes individuais, considerados como os nós ou os atores da rede, que ocupam posições no interior da estrutura associadas à divisão do trabalho dos diferentes agentes, conectados por ligações que determinam o grau de densidade ou difusão desses atores na rede, buscam a troca constante de benefícios mútuos, por 
meio de fluxos tangíveis (insumos e produtos) e até mesmo fluxos intangíveis (informações) (CASTILLA et al., 2000; BRITTO, 2002).

Podem ser pessoas, quando composta por pessoas que um indivíduo se relaciona, como por exemplo sua família, amigos, empregados, superiores hierárquicos, parceiros de negócios; como podem ser também interorganizacionais, consistindo na rede que uma organização constrói com outras organizações, sejam elas outras empresas, organizações de apoio, fornecedores, universidade, órgão públicos, dentre outros (BARNES, 1972; WELLMAN, 2007).

No prisma organizacional, Manuel Castells (2001) define redes como estruturas abertas, dinâmicas, passíveis de inovações sem comprometer o seu equilíbrio, e que podem expandir-se ilimitadamente, agregando novos "nós" desde que compartilhem dos mesmo objetivos e valores. $O$ debate sobre redes adquiriu maior consistência com as ideias apresentadas através da teoria de sistemas, que pressupõe que seja realizado o processo organizacional de forma a atender os requisitos do ambiente que está inserido.

Entendidas como instrumento estrutural de processos de cooperação e aprendizagem entre diferentes organizações, as redes interorganizacionais para Powell (1990) apresentam os fatores que levam as organizações a troca de informações, geração de confiança, estabilidade, segurança, reforçando o fator de promoção de aprendizagem. Essa forma de organização muitas vezes se faz necessário, pois como Cândido e Abreu (2000) salientam, as organizações de maneira isoladas não conseguiriam se desenvolver e/ou sobreviver frente ao excessivo crescimento da concorrência

Independentemente da forma, os estudos desenvolvidos para redes, caracterizam-se por analisar as relações que os atores estabelecem dentro e fora de sua própria estrutura a fim de alcançar objetivos em comum por intermédio da cooperação. Dessa forma, qualquer organização pode ser entendida e analisada como uma rede de múltiplas relações, tanto intraorganizacionais, na forma como os indivíduos interagem, trocam experiências e criam vínculos dos mais variados tipos; quanto 
interorganizacionais em relacionamentos com fornecedores, distribuidores, agências reguladoras e outras organizações (NOHRIA E ECCLES,1992).

\subsection{PROCESSO DE FORMAÇÃO E DESENVOLVIMENTO DE REDES}

O processo formação de redes está relacionada à sobrevivência organizacional (AMATO NETO, 1999). Os empreendimentos sociais coletivos buscam por parcerias e colaboração externa sob a forma de redes cada vez mais flexíveis, para proporcionarem condições de crescimento, ao passo que estimulem os processos de aprendizagem coletiva e de cooperação (KANTER, 2000).

Tanto a formação quanto o desenvolvimento de redes são marcadas por etapas relacionadas com a identificação dos objetivos comuns que os motivam. Nakano (2005 apud Oliver, 1990) afirma que, a formação de uma rede advém de várias motivações, como por exemplo imposições legais, compartilhamento de objetivos comuns, tentativa de maximizar a eficiência com a redução de custos, busca por estabilidade face às incertezas do ambiente competitivo e a legitimidade através de maior visibilidade, credibilidade, prestígio frente a organizações respeitadas em seu meio. Contudo, seja qual for a motivação, tanto nas concepções de uma rede quanto no seu desenvolvimento e continuidade, é necessário que haja alguns elementos como advertido por Leon (1998), como por exemplo a cultura de confiança em que a ética assume um papel fundamental.

Wegner e Padula (2008) apresentam um modelo geral de formação de uma rede interempresarial, que se adequa a proposta dessa pesquisa, que é a formação de uma rede para um empreendimento social coletivo. A proposta dos autores é composta por quatro fases, quais sejam: contatos iniciais, formatação, desenvolvimento e consolidação, como pode ser visto na Figura 1. 
Figura 1: Etapas na formação de redes

Contatos
iniciais

Fonte: adaptado de Wagner e Padula (2008)

Nesse modelo, a primeira medida que se deve adotar é estabelecer os contatos iniciais que são os potencias membros da rede através da identificação de problemas e dificuldades comuns, bem como a observação de oportunidades conjuntas de mercado. O próximo passo é a formatação da rede, que muitas das vezes é efetuada de maneira formal, por meio procedimentos e documentações jurídicos, que estipulará as normas e regras de conduta que todos os membros devem respeitar. Em seguida, após de fato a rede ser inaugurada, ela se desenvolve ao passo que seus integrantes elaboram e executam ações integradas que proporcionará a consolidação da rede com o passar do tempo, e é justamente nesse estágio que é possível a sua expansão (WAGNER e PADULA, 2008).

\section{METODOLOGIA}

A presente pesquisa é de caráter exploratória, com abordagem qualitativa. Efetuouse uma breve revisão bibliográfica dos assuntos referentes a empreendedorismo social, empreendedorismo social coletivo, redes sociais e formação e desenvolvimento de redes, com busca em seminário, publicações em plataformas periódicas de dados nacionais e internacionais como CAPES, Google Scholar, SciELO, SPELL® e Banco Digital de Teses e Dissertações BDTD. 
A partir do objetivo proposto no artigo, efetuou-se um estudo de caso, o qual para Yin (p. 32, 2005), é uma investigação empírica que "investiga um fenômeno contemporâneo dentro de seu contexto da vida real, especialmente quando, os limites entre o fenômeno e o contexto não estão claramente definidos. Siena (2001) acrescenta que "no estudo de caso são reunidas informações tão numerosas e detalhadas quanto possível com o intuito de apreender o todo do fenômeno".

Escolheu-se como empreendimento social coletivo a ser estudado a Associação dos catadores de materiais recicláveis de rua de Porto Velho - ASPROVEL, por ser a pioneira no seu ramo, por ser conhecida por proporcionar desenvolvimento sustentável, por ela ser a que tem mais destaque nos noticiários locais dentre as outra cooperativas de catadores de materiais recicláveis, e por seu presidente fundador se engajar com movimentos sociais, como é o caso do Movimento Nacional dos Catadores de Materiais Recicláveis - MNCR, em busca de legitimidade e parcerias para a sua associação.

Aplicou-se a técnica de entrevista em profundidade, que permite o máximo de liberdade e aprofundamento, e que possibilitou obter do entrevistado o que ele considera os aspectos mais relevantes do objetivo da pesquisa que lhe foi inicialmente apresentado. Richardson (2007) pontua que através da entrevista em profundidade é possível tanto obter informações do entrevistado quanto conhecer sua opinião. A entrevista em profundidade entrevista foi gravada e transcrita, e permitiu compreender os anseios que levaram a concepção da associação, a sua trajetória até os dias atuais, quais os parceiros e quais as suas contribuições.

Logo após a conclusão da entrevista, que foi realizada na sede da associação, foi aplicada a técnica da observação direta onde foi possível observar a chegada de um caminhão com matérias recicláveis doados por um órgão estadual, a triagem do material por alguns associados, a prensagem e passagem. Na ocasião também foi aplicada a técnica de análise documental, por meio do estatuto da associação onde foi possível verificar por exemplo a natureza jurídica e atividade principal e secundária, e também a ficha de cadastro dos catadores que permitiu observar a faixa etária e o grau de escolaridade. 


\section{RESULTADOS E DISCUSSÕES}

As redes sócias são complexas pois são um conjunto de pessoas conectadas e motivadas pelas amizades, necessidades ou relações de trabalho. Nas redes é possível compartilhamento de informações e construção de estruturas sociais, para o delineamento da pesquisa foi traçado um ator ego e as conexões com a rede social dele como demostrado na Figura 1 a formação da rede social da ASPROVEL.

Figura 2 - Rede Social ASPROVEL

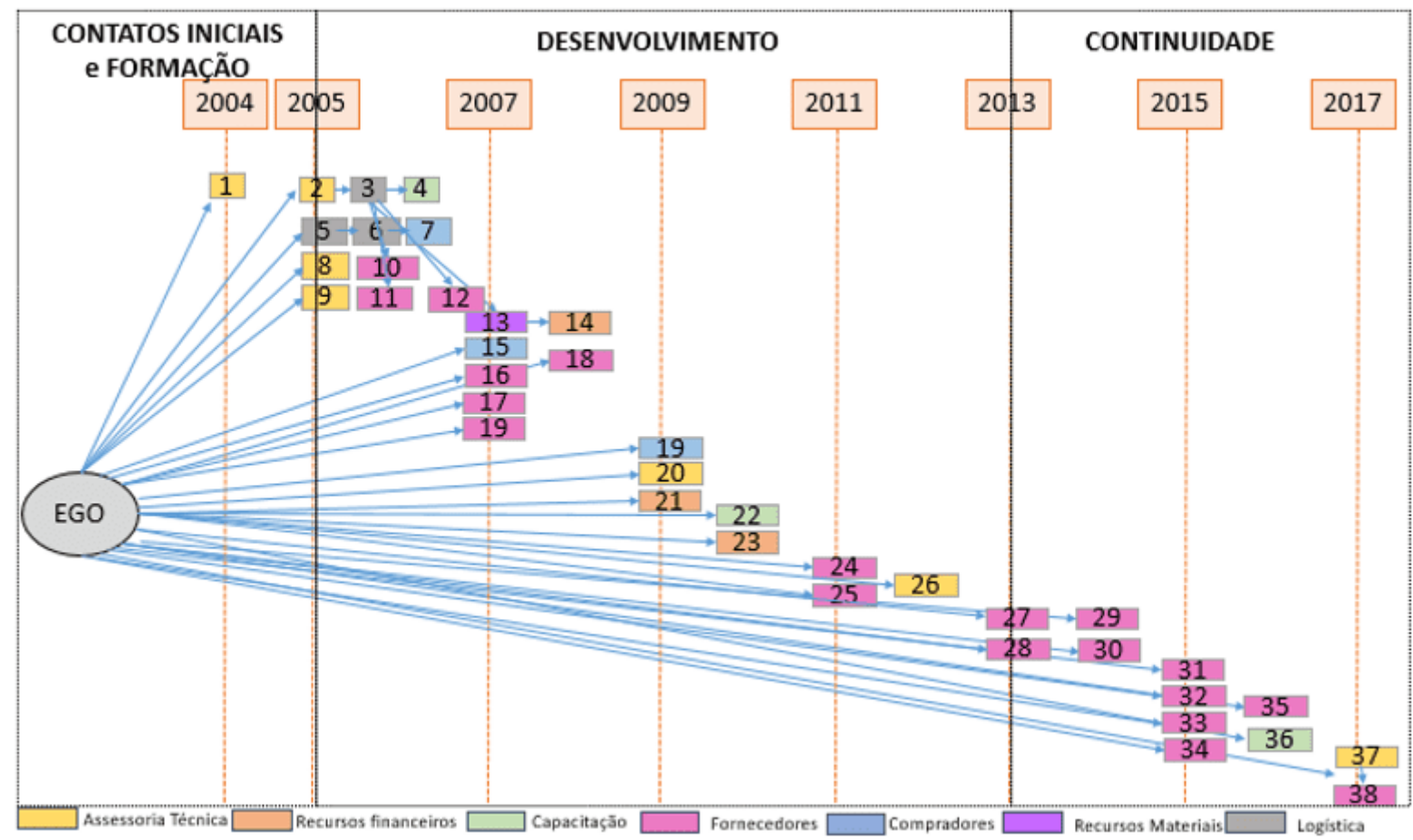

Fonte: Elaborado pelos autores

O ego da pesquisa é o senhor Geraldo Gonzaga de Lima, 59 anos, natural de Pernambuco, chegou a Porto Velho, capita de Rondônia, no início do ano de 2004 em busca do seu irmão, Gilvan Gonzaga de Lima (1), que já trabalhava desde 1994 como catador, especificamente catador de ferro e alumínio, apresentou o ofício ao seu irmão. No Início de 2005, o Instituto Nenuca de Desenvolvimento Sustentável - INSEA (2), que é uma ONG nacional de assessoria técnica e parceria a grupos comunitários na criação e no desenvolvimento de modelos de gestão ambiental e inclusão social, veio a cidade de Porto Velho em busca de cooperativas de catadores de matérias 
recicláveis que pudessem representar o estado em um evento de capacitação promovida pelo Movimento Nacional dos Catadores de Materiais Recicláveis - MNCR (4). Como a época não havia cooperativas desse ramo, o INSEA, juntamente com a Prefeitura Municipal de Porto Velho - PMPV (3), foram em busca de um representante de catador de lixão, e um catador de rua, onde o Senhor Geraldo foi contemplado.

Fundada em 03 de dezembro de 2005, a Associação dos Catadores de Materiais Recicláveis de Rua de Porto Velho - ASPROVEL iniciou suas atividades com 57 catadores associados, sendo 17 mulheres e 40 homens, com idades entre 18 e 54 anos e a maioria com o ensino fundamental incompleto, que antes sobrevivem da coleta de materiais retirados dos lixos domésticos em condições insalubres, e sentiam-se marginalizados. Iniciou-se uma cooperativa comunitária que permitiu que organizações, movimentos e consumidores na figura dos catadores, colaborassem na tentativa da promoção de melhoria de vida e inclusão social e econômica dos cidadãos locais (MONTGOMERY; DACIN e DACIN, 2012).

Ao retornar a Porto Velho, o senhor Geraldo foi buscou outras pessoas (5 e 6) que catassem além de ferro e alumínio, como era apenas com seu irmão, por perceber tanto o potencial lucrativo em outros materiais como plástico, papel e papelão, e por entender, após a capacitação do MNCR, a importância do aproveitamento de todos esses materiais para preservação do meio ambiente, bem como o valor que o serviço de catador de material reciclável tem perante a sociedade. Junto com seus novos amigos, foram em busca de comprador (7) para seus "novos" produtos. Esses novos amigos foram fundamentais também para contatar muitos outros catadores, que junto com a PMPV, e duas Instituições de Ensino Superior (8 e 9) do município, pudesse multiplicar as informações recebidas na capacitação do MNCR e articular a fundação da primeira associação de catadores de matérias recicláveis do município.

Pode-se observar que até dado momento efetuou-se duas das etapas do modelo geral de redes propostas por Wagner e Padula, 2008, quais sejam: o estabelecimento de contatos iniciais com a identificação de problemas e dificuldades em comuns, de uma lado a PMPV que tinha o lixo como um problema e do outro lado os catadores que viam no lixo a solução; Em seguida, com apoio do MNCR e Instituições de ensino 
superior do município que apoiaram com assessoria técnica e capacitação, iniciou-se a formação da rede não-formal de apoio a ASPROVEL conforme demonstrado no Quadro 2.

Quadro 2 - Instituições constantes na rede social

\begin{tabular}{|l|l|l|l|}
\hline POSIÇÃO & NOME & POSIÇÃO & NOME \\
\hline 1 & ICEA & $\mathbf{2 0}$ & "FRANÇA' \\
\hline 2 & PMPV & $\mathbf{2 1}$ & TRT \\
\hline 3 & MNCR & $\mathbf{2 2}$ & MPF \\
\hline 4 & Carlos & $\mathbf{2 3}$ & TCE \\
\hline 5 & Marinalva & $\mathbf{2 4}$ & MP \\
\hline 6 & Metal Norte & $\mathbf{2 5}$ & Izabel \\
\hline 7 & UNIR & $\mathbf{2 6}$ & TRT \\
\hline 8 & Faculdade São Lucas & $\mathbf{2 7}$ & TJ \\
\hline 9 & IBGE & $\mathbf{2 8}$ & Fecomercio \\
\hline 10 & CONAB & $\mathbf{2 9}$ & Incra \\
\hline 11 & Hidrelétrica Samuel & $\mathbf{3 0}$ & Lei \\
\hline 12 & Furnas & $\mathbf{3 1}$ & Governo \\
\hline 13 & Uchôa & $\mathbf{3 2}$ & Saulo \\
\hline 14 & Embrapa & $\mathbf{3 3}$ & Supermercado 1 \\
\hline 15 & Ibama & $\mathbf{3 4}$ & Supermercado 2 \\
\hline 16 & Dydyo & $\mathbf{3 5}$ & Paulo \\
\hline 17 & Shopping & $\mathbf{3 6}$ & Eco sustentável \\
\hline 18 & Amazon & $\mathbf{3 7}$ & Eco do Madeira \\
\hline 19 & IMA & $\mathbf{3 8}$ & Comunidades Ribeirinhas \\
\hline
\end{tabular}

Fonte: Elaborado pelos autores

No tocante, após inauguração da ASPROVEL feita formalmente por meio de estatuto, durante os anos de 2006 a 2013, ocorreu o desenvolvimento tanto da associação quanto da rede de apoio, por meio de ações integradas de membros da associação e 
de seu ambiente externo. O senhor Geraldo, nomeado presidente da associação, começou a participar de eventos municipais e estaduais voltados para a conscientização da preservação ambiental por meio da reciclagem, e dessa forma ganhou notoriedade nos noticiários locais. Em pouco tempo órgãos governamentais $(10,11,16,17,24,25)$ começaram a entrar em contato com a associação para formar parcerias, como também empresas privadas, uma fábrica de refrigerantes (18) e o primeiro e único shopping da cidade (19) inaugurado em 2008.

O período de desenvolvimento foi longo devido a algumas dificuldades enfrentadas pela associação, como a perda considerável de associados devido à criação de postos de trabalhos após a instalação das Usinas Hidrelétricas de Santo Antônio e Samuel, e a dois incêndios na sede da associação, um no ano de 2008 e outro no ano de 2010. Houveram também a criação de novas associações de catadores de materiais recicláveis, a ASSOCIAÇÃO UNIDA PELA VIDA, ASCOVIP e a CATANORTE. O Senhor Geraldo declara não ter abandonado a atividade, permanecendo na batalha em prol do meio ambiente e na busca da autonomia e autogestão dos catadores, seguindo o legado daqueles que iniciaram a atividade de catador na década de 50 . Contudo, nesse mesmo período a associação foi contemplada com recursos financeiro, meio por dois editais $(14,21$ e 23$)$, para compra de maquinarias e reconstrução e melhoria na sede.

Com o passar do tempo a associação se consolida com a retomada de seus associados e a integração de novos. A rede de apoio também se expande, com a inclusão de novos parceiros, uns como apenas como fornecedores de matérias $(27,28,29,30,31,32,33,34,35,38)$ e outros (36 e 37) com capacitação e até mesmo entrega de equipamentos de proteção individual e uniformes.

Sobre a quantidade de lixo que deixa de contaminar o meio ambiente, senhor Geraldo estima que, em Porto Velho cerca de 150 toneladas de materiais recicláveis são aproveitados pelos catadores, sendo a ASPROVEL responsável por aproveitar cerca 95 toneladas, contribuindo assim para ampliar a vida útil do aterro sanitário, reduzindo a extração de matéria prima, preservando o meio ambiente e para a cidade mais limpa, 
propiciando o entrelaçamento da economia com a ecologia rumo ao desenvolvimento sustentável.

\section{CONSIDERAÇÕES FINAIS}

O principal objetivo da pesquisa era o de demonstrar a importância da rede social na trajetória de um empreendedorismo social coletivo, considera-se o objetivo como alcançado uma vez que foi demostrado como a rede social construída através do ego foi fundamental para a manutenção e crescimento do empreendimento social coletivo representado nessa pesquisa pela associação ASPROVEL. Fica evidente na pesquisa que a força da associação está na rede de apoio e na legitimação que possui diante a sociedade e não nos seus associados, vez que a cooperação e a intenção de estar junto para conseguir melhores posições no mercado ainda não é mais forte que o medo de estar junto e perder uma vez para ganhar muitas.

O estudo realizado apresenta limitações importante quanto à cronologia dos fatos, as principais informações foram adquiridas em forma de entrevista como o presidente da associação que por questão do tempo em que aconteceu os fatos que estavam sendo narrados, poderia não recordar, de outros atores que foram importantes para a formação do empreendimento social coletivo.

Para pesquisas futuras sugere-se que se faça um trabalho quanto aos elos fortes e fracos que existem na associação e quais desses elos são fundamentais para a manutenção dela mesmo com o mínimo de associados atuante.

\section{REFERENCIAS}

AMATO NETO, J.: Redes de cooperação produtiva: antecedentes, panorama atual e contribuições para uma política industrial. Tese (Livre Docência) - Escola Politécnica, Universidade de São Paulo, São Paulo, 1999

AUSTIN, J., H. Stevenson and J. Wei-Skillern: 'Social and Commercial Entrepreneurship: Same, Different or Both?', Entrepreneurship Theory and Practice 30(1), 1-22. 2006 
BESSANT, J.; TIDD, J. Inovação e empreendedorismo. Porto Alegre: Bookman, 2009. Tradução de: Elizamari Rodrigues Becker et al.

BRITTO, J. Cooperação interindustrial e redes de empresas. In: KUPFER, D. e HASENCLEVER, L. (Org.). Economia industrial: fundamentos teóricos e práticos no Brasil. Rio de Janeiro: Campus, 2002.

BROUARD, F.; LARIVET, S. Essay of Clarifications and Definitions of the Related Concepts of Social Enterprise, Social Entrepreneur and Social Entrepreneurship. In: FAYOLLE; A.; MATLAY, H. (Ed.). Handbook of Research on Social Entrepreneurship. Cheltenham: Edward Elgar, p. 29-56, 2011.

CÂNDIDO, G. A.; ABREU, A. F. Os conceitos de redes $e$ as relações interorganizacionais: um estudo exploratório. In: Encontro da ENAMPAD, 24., 2000, Rio de Janeiro. Anais. Rio de Janeiro: ANPAD, 2000. Disponível em <http://www.anpad.org.br/admin/pdf/enanpad2000-org-783.pdf>. CASTELLS, M. A sociedade em rede. in A era da informação: Economia, sociedade e cultura, v.1. 5. ed. São Paulo: Paz e Terra, 2001.

CHOUINARD, O.; FORGUES, É. Collective entrepreneurship and regional development: case Study of a New Brunswick cooperative. Journal of Rural Cooperation, vol. 30, no. 2, pp. 79-94, 2002.

CONNELL, D. J. Collective entrepreneurship: in search of meaning. December, 1999.

CORRÊA, V. S.; VALE, G. M. V. Redes sociais, perfil empreendedor e trajetórias. In: Revista de Administração da USP, São Paulo, v.49, n.1, p.77-88, jan./fev./mar./ 2014

GLIEDT, T.; PARKER P. 'Green Community Entrepreneurship: Creative Destruction in the Social Economy', International Journal of Social Economics 34(8), 538-553, 2007.

GREVE, A.; SALAFF J. W. 'Social Networks and Entrepreneurship', Entrepreneurship Theory and Practice 28(1), 1-22, 2003. 
JUNQUEIRA, L. A. P. Intersetorialidade, transetorialidade e redes sociais na saúde. Revista de Administração Pública, Rio de Janeiro, FGV, v. 34, n. 6, p. 35-45, nov.-dez. 2000 .

LEON, M. E. Uma Análise de Redes de Cooperação das Pequenas e Médias Empresas do Setor das Telecomunicações. Dissertação Mestrado, Engenharia de Produção da Escola Politécnica da Universidade de São Paulo, Dez., 1998.

MAIR, J.; MARTÍ, I. Social entrepreneurship research: a source of explanation, prediction, and delight. Journal of World Business, vol. 41, pp. 36-44, 2006.

MARTELETO, R. M. Análise de redes sociais: aplicação nos estudos de transferência da informação. Ciência da Informação, Brasília, DF, v. 30, n. 1, p. 71-81, jan.-abr. 2001.

MITCHELL, R. K., L. Busenitz, T. Lant, P. P. McDougall, E. A. Morse and J. B. Smith: 'Toward a Theory of Entrepreneurial Cognition: Rethinking the People Side of Entrepreneurial Research', Entrepreneurship Theory and Practice 27(2), 93-104. 2002.

MONTGOMERY, A, W.; DACIN, P. A.; DACIN, M. T. Collective Social Entrepreneurship: Collaboratively Shaping Social Good. Journal of Business Ethics, v. 111 , p. $375-388,2012$

NAHAPIET, J.; GHOSHAL S. 'Social Capital, Intellectual Capital and the Organizational Advantage', The Academy of Management Review 23(2), 242-266, 1998.

NAKANO, D. N. Fluxos de conhecimentos em redes interorganizacionais: conceitos e fatores de influência. In: Redes entre organizações: domínio do conhecimento e da eficiência operacional. AMATO NETO, João (organizador). São Paulo: Atlas, 2005. NOHRIA, N. Is a network perspective a useful way of studying organizations? In: NOHRIA, N. \& ECCLES, R. G. (Ed.). Networks and organizations: structure, form, and action. Boston, Massachusetts: Harvard Business School Press, 1992, p. 1- 
22. OLIVEIRA, V.M; CÂNDIDO, G, A. As formas de organizações em redes e a atuação dos brokers. Encontro Nacional de Engenharia de Produção, Fortaleza-CE, 2006. Anais eletrônico. Disponível em <http://www.abepro.org.br/biblioteca/ENEGEP2006_TR530358_7011.pdf>.

PEDROZO, E. Á.; SILVA, T. N. da. Cooperativa, uma organização diferenciada rumo à sustentabilidade. ANÁLISE. Porto Alegre, v. 10, n. 2, pp. 47-74, 1999.

PEREDO, A. M.; MCLEAN, M. Social entrepreneurship: A critical review of the concept. Journal of World Business, vol. 41, pp. 56-65, 2006.

POWELL, W. W., KOGUT, K. W, SMITH-DEORR. Interorganizational collaboration and the locus of innovation: networks of learning in biotechnology. 1996. In: JONES, Gareth, R. Teoria das organizações/Gareth R. Jones; tradução Luciane Pauleti e Daniel Vieira. São Paulo: Pearson Education do Brasil, 2010.

REYNOLDS, Paul D. Understanding business creation: serendipity and scope in two decades of business creation studies. Small Business Economics, vol. 24, pp. 359364, 2005.

RICHARDSON, R. J. Pesquisa social: métodos e técnicas. 3. ed. São Paulo: Atlas, 2007.

RING, J. K.; PEREDO, A. M.; CHRISMAN, J. J. Business networks and economic development in rural communities in the united states. Entrepreneurship Theory \& Practice Journal, 2010.

SIENA, O. Metodologia da pesquisa científica: elementos para elaboração e apresentação de trabalhos. Porto Velho: UNIR, 2007.

SINGER, P. Economia solidária: um modo de produção e distribuição. In: SINGER, Paul; SOUZA, A. (orgs.). A Economia solidária no Brasil: a autogestão como resposta ao desemprego. São Paulo: Contexto, 2000. 
SPEAR, R. Social entrepreneurship: A different model? In: International Journal of Social Economics, 33(5/6), 399-410. 2006.

SUD, M., et al. Social entrepreneurship: The role of institutions. Journal of Business Ethics, 85, 201-216. 2009.

THOMPSON, J. L.'The World of the Social Entrepreneur', The International Journal of Public Sector Management 15(5), 412-431, 2002.

VANSANDT, C. V. (2009). Enabling the original intent: Catalysts for social entrepreneurship. Journal of Business Ethics, 90, 419-428. 2009.

WAGNER, D., PADULA, A. D. Quando as redes falham: um estudo sobre o fracasso na cooperação interorganizacional. In: ENCONTRO ANUAL DA ANPAD, 32, 2008, Rio de Janeiro. Anais... Rio de Janeiro: ANPAD, 2008. 1 CD.

YIN, R. K. Estudo de caso. Planejamento e métodos. 3. ed. Tradução de Daniel Grassi. Porto Alegre: Bookman, 2005.

Enviado: Maio, 2020.

Aprovado: Outubro, 2020. 